\title{
Working conditions mediate the association between social class and physical function in older age in Sweden: a prospective cohort study
}

Nikita Pandey ${ }^{1}$, Alexander Darin-Mattsson ${ }^{1}$ and Charlotta Nilsen ${ }^{1,2^{*}}$

\begin{abstract}
Background: Global demographics are changing as societies all over the world are aging. This puts focus on maintaining functional ability and independence into older age. Individuals from lower social classes are at greater risk of developing limitations in physical function later in life. In this study, we investigated the mediating role of working conditions in the association between occupation-based social class and physical function measured as self-reported mobility limitations and objectively measured physical impairment in older age.
\end{abstract}

Methods: Two Swedish surveys, linked at the individual level, were used ( $n=676-814$ depending on the outcome). Follow-up time was 20-24 years. Multiple logistic regression analyses were performed with adjustments for age, sex, level of education, mobility, and health problems at baseline. This was followed by analyses of the size of the mediating effect of working conditions.

Results: Working conditions seem to mediate $35-74 \%$ of the association between social class and physical impairment in older age. The pattern of mediation was primarily driven by passive jobs, i.e., low psychological demands and low control, among blue-collar workers. Working conditions did not mediate the association between social class and self-reported mobility limitations in older age.

Conclusions: The results of this study indicate that working conditions are important in combating the social gradient in healthy aging, contributing to the evidence regarding the magnitude of impact exerted by both the physical and psychosocial work environment separately and in conjunction.

Keywords: Psychosocial working conditions, Physical working conditions, Older age, Physical impairment, Mobility, Physical function, Social class, Healthy aging, Longitudinal, Sweden

\footnotetext{
* Correspondence: charlotta.nilsen@ki.se

'Aging Research Center (ARC), Karolinska Institutet/Stockholm University,

SE-171 65 Stockholm, Sweden

${ }^{2}$ Stress Research Institute, Stockholm University, SE-106 91 Stockholm,

Sweden
}

C C The Author(s). 2020 Open Access This article is licensed under a Creative Commons Attribution 4.0 International License, which permits use, sharing, adaptation, distribution and reproduction in any medium or format, as long as you give appropriate credit to the original author(s) and the source, provide a link to the Creative Commons licence, and indicate if changes were made. The images or other third party material in this article are included in the article's Creative Commons licence, unless indicated otherwise in a credit line to the material. If material is not included in the article's Creative Commons licence and your intended use is not permitted by statutory regulation or exceeds the permitted use, you will need to obtain permission directly from the copyright holder. To view a copy of this licence, visit http://creativecommons.org/licenses/by/4.0/. The Creative Commons Public Domain Dedication waiver (http://creativecommons.org/publicdomain/zero/1.0/) applies to the data made available in this article, unless otherwise stated in a credit line to the data. 


\section{Background}

Global demographics are changing as societies are aging. Within the EU, it is estimated that nearly $30 \%$ of the total population will be 65 years or older by 2060 [1]. While this is a good indication of the success of modern medicine, it raises major concerns regarding global preparedness to accommodate the ensuing shift in social dynamics. Recognizing the increasing care need that follow a growing older population [2], a global strategy and action plan for aging and health was published [1], defining healthy aging as "the process of developing and maintaining the functional ability that enables wellbeing in older age". Evidence suggests that limited physical function restricts such active participation of older adults within society [3]. Physical function decreases with age. Particularly in the age group of $80+$ [4]. Deterioration of physical function, such as muscle function, aerobic capacity, and postural balance [5] leads to impaired ability to perform daily activities [6] and has been associated with reduced quality of life [7]. Therefore, to preserve physical function in older adults is a major public health concern.

A staggering amount of research confirms that individuals from lower social classes are at greater risk of developing adverse health outcomes in older age than those from higher social classes [8-10]. Health inequality persists across populations throughout the world. Variations in physical function in older age follow a similar pattern [11]. As suggested by the accumulation of advantage and disadvantage (CAD) theory [12], the chain of disadvantages derived from belonging to a lower social class throughout the life course have been shown to further induce health inequalities in later life [10]. For example, working conditions are often a consequence of an individual's occupational social class. People who belong to a lower social class, such as blue-collar workers, are more likely to be exposed to adverse psychosocial working conditions throughout work life, including workrelated stress, repetitive work, low influence at work, as well as physically demanding working conditions [13]. Hence, work is an area that is central to reducing inequalities in health outcomes [14]. There is also growing evidence of a long-term association between adverse working conditions and limitations in physical function in older age that persist after adjusting for socioeconomic factors [15-17]. Chronic stress derived from the work environment may cause damage to the physical body via disruptions of metabolism, blood pressure, hormone, and immune function [18] that may, in turn, negatively impact physical function in older age. Moreover, exposure to high physical workload has been associated with musculoskeletal pain and lower physical function in retirees that may cause long-term physical damage to the body [19].
The role of working conditions on the social gradient of health is well-established [20]; however, the objectives, parameters, and methodologies used in evaluating this relationship largely differ [21-23]. Among studies that examine the mediating role of working conditions in relation to social class, a common drawback is the lack of long-term evidence, as most studies either have a short period of follow-up or measure the outcomes among cohorts that retain generally good physical function by excluding the frail oldest old. Our study aims to overcome these challenges by utilizing a long period of follow-up and measuring the outcomes when the participants have reached a high age and a high prevalence of physical limitations. In this study, the role of working conditions on the social gradient of physical function in older age was assessed 20 years later. The prospective nature of the data used, and the high participant response rates, provide a unique opportunity to examine long-term associations. For this purpose, the following research questions were investigated: Is social class associated with late-life physical function 20-24 years later? If so, do physical and psychosocial working conditions mediate such association?

\section{Methods}

\section{Data and analytic sample}

Two linked nationally representative surveys conducted in Sweden were used: The Level of Living Survey (LNU) [24] and the Swedish Panel Study of Living Conditions of the Oldest Old (SWEOLD) [25]. The first LNU sample was selected in 1968. New waves were conducted in 1974, 1981, 1991, 2000 and 2010. The age range of the sample was $18-75$ years. To represent the Swedish population, randomized quota sampling was conducted to include immigrants and young people. When crossing the upper age limit of 75 years, participants were reinterviewed in the SWEOLD study, which was conducted in five waves: 1992, 2002, 2004, 2011 and 2014. For LNU, structured face-to-face interviews were conducted with professional interviewers. SWEOLD primarily followed the same procedure. However, if a participant had a cognitive impairment or was unable to participate, proxy interviews were conducted with either the spouse, close relative, friend or relevant healthcare professional.

Data used in this study comprises three linked sets of data combined into one longitudinal dataset. Data from LNU 1968 were linked with re-interviews of the sample in SWEOLD 1992 (linkage 1), data from LNU 1981 were linked with SWEOLD 2002 (linkage 2) and data from LNU 1991 were linked to SWEOLD 2011 (linkage 3). The three linkages were compiled in one dataset and analyzed together. If respondents from the baseline in 1968 or 1981 did not respond to any of the questions, the 
same respondent's answer from LNU 1974 was used instead. Non-response in baseline 1991 was replaced with answers from LNU 1981. However, this imputation did not exceed $10 \%$ in any variable. Response rates in LNU range from 78 to $91 \%$, and in SWEOLD, from 86 to $95 \%$.

In order to follow-up the participants from LNU in SWEOLD, they had to be 53 years or older at baseline. Long-term unemployed, students and housewives were excluded from the analyses because their working conditions could not be assessed. Baseline item nonresponse $(n=46,4.9 \%)$ reduced the sample from 891 to 845 participants and item nonresponse at follow-up further reduced it to 676 or 814 depending on outcomes (Fig. 1). Age varied between 53 and 72 years (mean age 59) at baseline and 77 and 95 years (mean age 81) at follow-up.

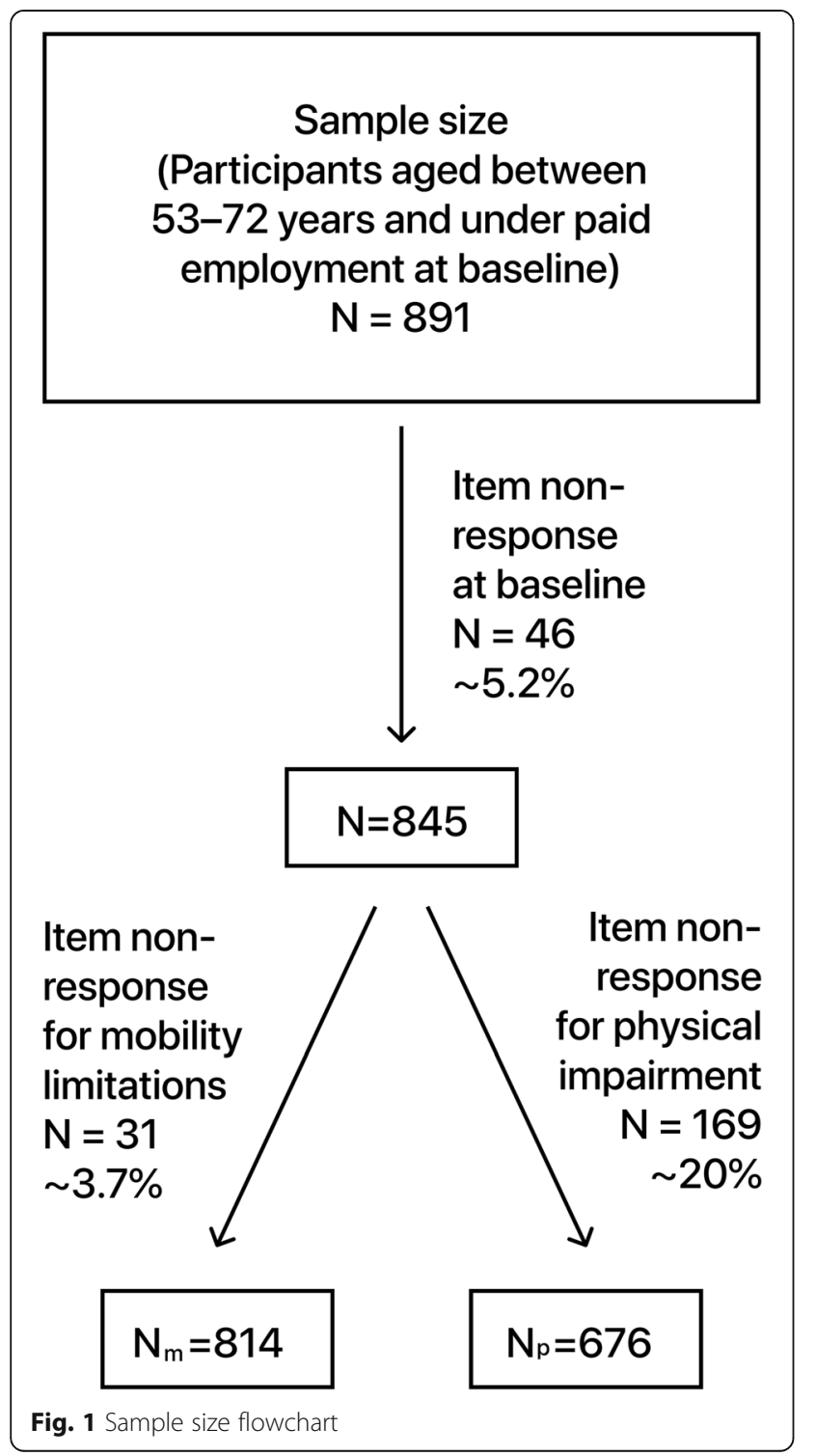

\section{Measures of physical function in older age}

The main outcome variable was physical function in older age measured using two components available in the SWEOLD study: mobility limitations and physical impairment, used in earlier research $[8,15-17,19]$. Mobility limitations were assessed with the responses to three dichotomous "yes/no" questions: "Can you walk 100 meters briskly without difficulty?", "Can you walk up and down stairs with no problem?", and "Can you stand without support?". The combined responses were coded into a three-value ordinal scale wherein $0=$ "no mobility limitations" (completed all activities without difficulty), 1 = "mild" (unable to complete one of the activities without difficulty), and $2=$ "severe" (difficulty in completing two or all three activities). Physical impairment was assessed by combining nine objective tests as follows: Picking up a pen from the floor, lifting 1 kilogram, touching the left ear with the right hand, touching the right ear with the left hand, touching the left toes with the right hand, touching the right toes with the left hand, placing both hands under the thighs/bottom, turning both palms up and down and getting up from a chair with arms crossed. The respondents were categorized on each task as "managed without difficulty," "managed with difficulty," and "did not manage." To increase power, the resultant variable was dichotomized ("absent" i.e. participant managed all tasks without help, and "present" participant was unable to manage all tasks without help. The participants' responses on Activities of Daily Living (ADL), recorded in the SWEOLD surveys, were used to impute missing values. Participants who were unable to carry out one or more ADL (e.g. dressing/undressing, bathroom visits, eating) were coded as "did not manage" based on the theoretical assumption that they were unable to participate in the physical performance tests $(n=34)$.

\section{Measures of social class}

Occupational social class was assessed at baseline. Occupation was categorized in accordance with the official Swedish socioeconomic classification (SEI) made by Statistics Sweden, and have been previously published [8, 10, 16]. This classification resembles the internationally well-known Erikson, Goldthorpe, and Portocarero's (EGP) schema [26]. In order to include small-scale farmers and entrepreneurs, as well as allocate ranks and make social class an ordinal variable, the SEI categories for self-employed individuals were regrouped. The social class variable was coded as unskilled blue-collar workers, skilled blue-collar workers, including small-scale farmers and entrepreneurs with no employees, lower white-collar workers, including medium-scale farmers and entrepreneurs with one to nine employees, and upper whitecollar workers, including large-scale farmers, academic 
professionals and entrepreneurs with at least $10 \mathrm{em}$ ployees. The SEI coding incorporates educational achievement in the ordering of occupations as part of the classification criteria.

\section{Measures of working conditions}

Physical working conditions were assessed at baseline using a six-item index consisting of exposure to various components during the week before the interview. These were: "Do you have to be capable of lifting 60 kilos (heavy lifting) at your work?" (yes/no), "Are you exposed to heavy vibrations at your work?" (yes/no), "Is your job physically demanding?" (yes/no), "Do you sweat every day?" (yes/no), "Are you exposed to poison/acid/explosives?" (yes/no), "Are you exposed to gas, smoke or dust at your work?" (yes/no). The responses were then grouped into three categories. If participants responded negatively to all questions, they were coded as "no exposure"; if they responded "yes" to two or less questions, they were coded as "low exposure" and positive responses to more than two questions were coded as "high exposure." This categorization was made to preserve power as few participants were exposed to all components. Psychosocial working conditions were assessed at baseline through responses to selfreported yes/no questions and categorized based on the job demand-control model [27]. Demand was derived from the questions "Is your job psychologically demanding/taxing?" and "Is your job hectic?" (yes/no). To answer "yes" to both questions was classified as psychologically demanding. Control consists of personal schedule freedom (decision-making authority) and intellectual discretion (skill discretion). In this study, control was measured through intellectual discretion exclusively, by the questions "What is the level of education required by your job?" and "Is your job monotonous?". Based on the combined responses, jobs were categorized as: repetitious/ monotonous, not repetitious/monotonous and minimum skill level, not repetitious/monotonous and 1-4 years of training (skill level required); and not repetitious/monotonous and more than 4 years of training (skill level required). This was dichotomized into low and high control, in which repetitious/monotonous work and nonrepetitious/monotonous work with a minimum skill level was coded as "low control" and the other two were coded as high control." The demand and control variables were then combined to form four job categories: "passive" = low control and low demand, "high-strain" = low control and high demand, "low-strain" = high control and low demand, and "active" = high control and high demand.

\section{Covariates}

Age (continuous) and sex (binary) were retrieved from the registers and confirmed during the interviews. Mobility at baseline was created in the same manner as described for mobility limitations in old age. Health problems at baseline were assessed using an index of selfreported diseases and symptoms experienced over the last 12 months (pain in shoulders, back, hips, joints and/or stomach, cardio-vascular diseases and symptoms, including hypertension, chest pain, swollen legs, myocardial infarction and heart failure, diabetes, leg ulcer, dizziness, breathlessness, fatigue and sleep problems). Education was assessed by highest level of education at baseline and divided into two groups: compulsory and beyond compulsory (i.e., vocational, upper secondary, and university).

\section{Statistical analyses}

Stata version 14 was used for all analyses. Binary and ordered logistic regression were used to investigate associations between independent and dependent variables. The proportional odds assumption was tested using generalized ordered logistic regression and approved. To test if the three linkages could be merged into one, we analyzed the linkages separately. Although estimate size and significance level slightly varied between the three linkages, the associations were in the same direction. Also, interaction between linkage and social class was tested. The interactions were statistically non-significant. Thus, the three linkages were merged into one data set to increase power. Supplementary analyses were conducted by including an interaction term between sex and social class. The interaction term was only statistically significant for one out of the 28 interactions, likely by chance. The only statistically significant interaction showed that women in lower white-collar occupations reported more mobility limitations in older age than men. Thus, we analyzed women and men together. All analyses were adjusted for baseline characteristics: age, sex, mobility and health problems (Model 1). Model 2 was additionally adjusted for physical working conditions. Model 3 was adjusted like Model 1 and additionally for psychosocial working conditions. Model 4 was adjusted like model 1 and additionally for physical and psychosocial working conditions.

KHB (Karlson, Holm, and Breen) is a user command in STATA that conducts mediation analyses of a variable in the relationship between an independent and dependent variable by comparing the beta coefficients of two nested non-linear probability models [28]. The output is in the form of total effects, direct effects and indirect effects. When there is an indirect effect, but no direct effect, it is called 'full mediation'. When there are both direct and indirect effects, it is called 'partial mediation' [29].

\section{Results}

\section{Population characteristics}

Table 1 illustrates that blue-collar workers had the greatest exposure to adverse physical working 
Table 1 Descriptive statistics at baseline

\begin{tabular}{|c|c|c|c|c|c|}
\hline \multicolumn{6}{|l|}{ Occupational social class } \\
\hline & Unskilled blue-collar & Skilled blue-collar & Lower white-collar & $\begin{array}{l}\text { Upper } \\
\text { white-collar }\end{array}$ & Total (n) \\
\hline Total, n (\%) & $285(33.73)$ & $158(18.70)$ & $197(23.31)$ & $205(24.26)$ & 845 \\
\hline Mean age (SD) & $59(3.30)$ & $60(3.87)$ & $60(3.38)$ & $59(3.22)$ & $59(3.42)$ \\
\hline \multicolumn{6}{|l|}{ Sex, $n(\%)^{b}$} \\
\hline Women & $190(66.7)$ & $35(22.2)$ & $96(48.7)$ & $74(36.1)$ & $395(46.7)$ \\
\hline Men & $95(33.3)$ & $123(77.8)$ & $101(51.3)$ & $131(63.9)$ & $450(53.3)$ \\
\hline \multicolumn{6}{|c|}{ Physical working conditions, $\mathrm{n}(\%)^{\mathrm{b}}$} \\
\hline No exposure & $63(22.1)$ & $31(19.6)$ & $100(50.8)$ & $137(66.8)$ & $331(39.2)$ \\
\hline Low exposure & $147(51.6)$ & $52(32.9)$ & $51(25.9)$ & $58(28.3)$ & $308(36.4)$ \\
\hline High Exposure & $75(26.3)$ & $75(47.5)$ & $46(23.3)$ & $10(4.9)$ & $206(24.4)$ \\
\hline \multicolumn{6}{|c|}{ Psychosocial working conditions, $\mathrm{n}(\%)^{\mathrm{b}}$} \\
\hline Passive & $204(71.5)$ & $94(59.5)$ & 78 (39.6) & $18(8.8)$ & $394(46.6)$ \\
\hline High-strain & $43(15.1)$ & $18(11.4)$ & 39 (19.8) & $19(9.2)$ & $119(14.1)$ \\
\hline Low-strain & $21(7.4)$ & $34(21.5)$ & $50(25.4)$ & $83(40.5)$ & $188(22.2)$ \\
\hline Active & $17(6.0)$ & $12(7.6)$ & $30(15.2)$ & $85(41.5)$ & $144(17.0)$ \\
\hline \multicolumn{6}{|c|}{ Level of education, $\mathrm{n}(\%)$} \\
\hline Compulsory & $160(78.1)$ & $97(49.2)$ & $48(30.4)$ & $51(17.9)$ & $356(42.1)$ \\
\hline Beyond compulsory & $45(22.0)$ & $100(50.8)$ & $110(69.6)$ & $234(82.1)$ & $489(57.9)$ \\
\hline \multicolumn{6}{|c|}{ Health problems at baseline, $n(\%)^{b}$} \\
\hline None or mild & $224(78.6)$ & $134(84.8)$ & $173(87.8)$ & $191(93.2)$ & $722(85.4)$ \\
\hline Severe & $61(21.4)$ & $24(15.2)$ & $24(12.2)$ & $14(6.8)$ & $123(14.6)$ \\
\hline \multicolumn{6}{|c|}{ Mobility at baseline, $\mathrm{n}(\%)^{\mathrm{b}}$} \\
\hline Unrestricted & $214(75.1)$ & $126(79.7)$ & $159(80.7)$ & $183(89.3)$ & $682(80.7)$ \\
\hline Restricted & $71(24.9)$ & $32(20.3)$ & 38 (19.3) & $22(10.7)$ & 163 (19.3) \\
\hline
\end{tabular}

SD Standard deviation, $n$ Analytic size

${ }^{a}$ Row percentage

${ }^{\mathrm{b}}$ Column percentage

conditions. Moreover, almost one half of the analytic sample (46.6\%) was employed in passive jobs and unskilled blue-collar workers had the highest percentage (71.5\%). Around one-fifth of unskilled blue-collar workers (21.4\%) suffered from severe health problems at baseline and this proportion decreased in magnitude with every consecutive social class to $6.8 \%$ among upper white-collar workers. A similar pattern was observed with mobility limitations measured at baseline. About $82 \%$ among upper white-collar workers had an education level beyond compulsory, while the frequency was only $22 \%$ among unskilled blue-collar workers.

Table 2 illustrates a clear gradient in mobility limitations in older age, where unskilled blue-collar workers reported the most severe mobility limitations (28.2\%) and upper white-collar workers reported the least (12.0\%). The proportion between those who managed performance tests and those who did not differed between unskilled blue-collar workers (49.3\%) and upper white-collar workers (27.9\%).
Social class and physical function in older age

Although all associations did not meet traditional thresholds for declaring statistical significance $(p<.05)$, the basic pattern emerging in Table 3 suggest that in reference to upper white-collar workers, all other social classes were associated with greater odds of developing limited physical function in older age (i.e. self-reported mobility limitations and objective tests of physical impairment) when adjusted for covariates. Particularly, skilled blue-collar workers had higher odds of developing mobility limitations (OR 1.73, CI 1.09-2.73) and lower white-collar workers had higher odds of developing physical impairment (OR 1.67, CI 1.04-2.68) in older age (Table 3, model 1). On further adjusting for physical working conditions at baseline (model 2), the association between occupational social class and mobility limitations strengthened, but showed attenuation with physical impairment (Table 3, model 2).

Adjusting for psychosocial working conditions did not alter the association between social class and mobility 
Table 2 Descriptive statistics at follow-up

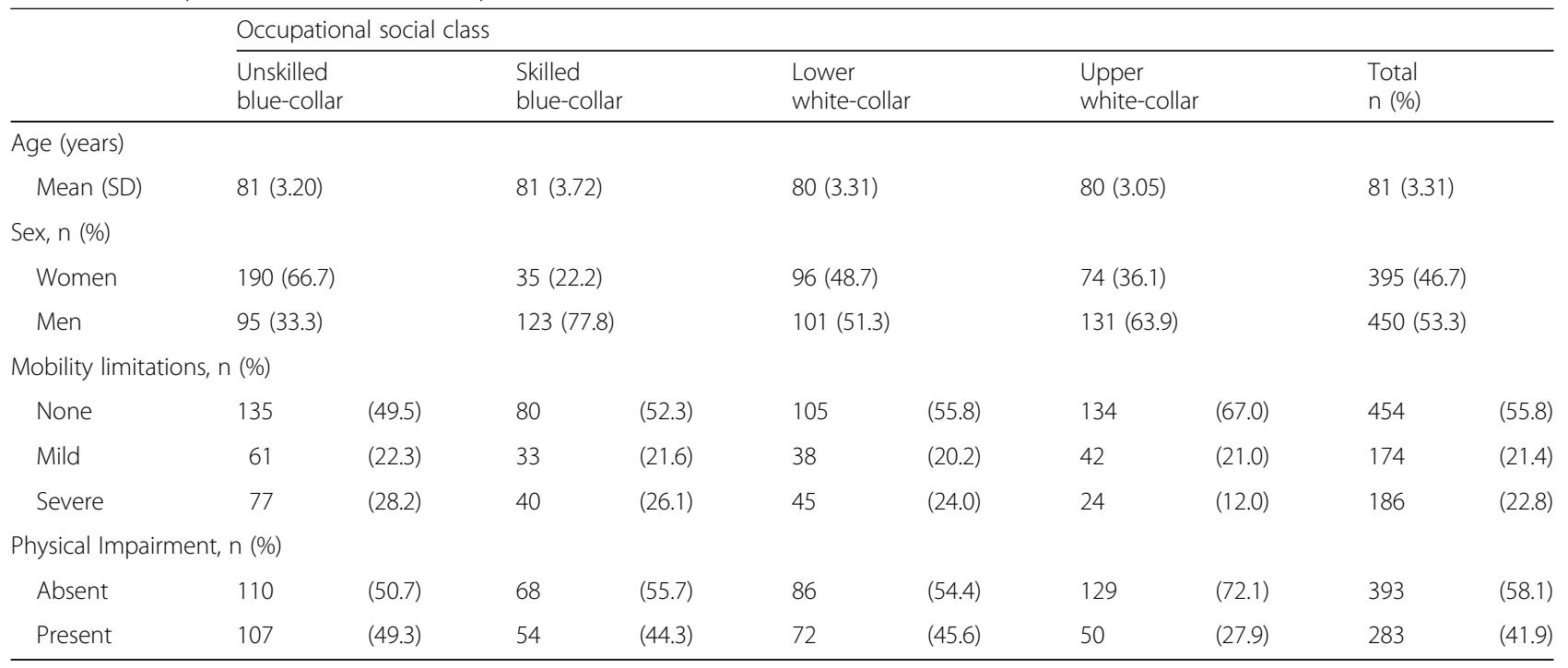

SD Standard Deviation, $n$ Analytic size

limitations in older age (Table 3, model $3 \mathrm{~b}$, and $3 \mathrm{~d}$ ). However, adjusting for passive or low-strain jobs attenuated the association between social class and physical impairment in older age (Table 3, model 3a and 3c).

After adjusting for both physical and psychosocial working conditions in model 4 (Table 3), the association between social class and physical impairment in older age became statistically non-significant.

\section{The mediating role of working conditions}

Decomposing the association between social class and physical function in older age (i.e. mobility limitations and physical impairment) using physical and psychosocial working conditions assessed separately revealed that the indirect effects did not reach traditional threshold for statistical significance $(p<.05)$ (Table 4). However, a negative mediation effect was observed among blue-collar workers $(p<.10)$ in relation to mobility limitations in older age. Among blue-collar workers, $-26.4 \%$ (skilled blue-collar workers) and $-31.9 \%$ (unskilled blue-collar workers) of the total effect seem to be attributable to physical working conditions ("partial mediation," i.e. both direct and indirect effects). Moreover, passive jobs mediated $(p<.10)$ the association between blue-collar workers and physical impairment in older age (Table 4, model 3a). Among blue-collar workers, $27.6 \%$ (skilled blue-collar workers) and $45.7 \%$ (unskilled blue-collar workers) of the total effect is attributable to passive jobs ("full mediation," i.e. indirect effect only; Table 4, model 3a). Low-strain jobs mediated $(p<.10)$ the association between unskilled blue-collar workers and mobility limitations by $23.38 \%$ (full mediation; Table 4, model 3c). High-strain jobs or active jobs did not mediate the association between social class and physical impairment in older age (Table 4, model 3b, and 3d).

An investigation of the combined mediating role of physical and psychosocial working conditions between social class and physical impairment in older age showed full mediation, in which both physical and psychosocial working conditions contributed. With upper white-collar workers as a reference, $35 \%$ of the total effect was attributable to working conditions among lower white-collar workers $(p=.051 ; 13 \%$ attributable to physical working conditions and $23 \%$ attributable to psychosocial working conditions). Although the total effect did not reach traditional thresholds for statistical significance $(p<.05)$, the indirect effect suggest that $51 \%$ of the total effect among skilled blue-collar workers was attributable to working conditions $(25 \%$ attributable to physical working conditions and $26 \%$ attributable to psychosocial working conditions) and $74 \%$ of the total effect among unskilled blue-collar workers was attributable to working conditions (28\% in physical working conditions and $45 \%$ in psychosocial working conditions; Table 4, model 4). No statistically significant mediating effects of working conditions were found in the association between social class and mobility limitations when physical and psychosocial working conditions were analyzed together (Table 4, model 4).

\section{Discussion}

This study examined the association between occupational social class and physical function in older age and attempted to disentangle this association by quantifying the mediating role of working conditions. In short, upper white-collar workers had lower odds of physical 
Table 3 Association between occupational social class and physical function in older age

\begin{tabular}{|c|c|c|c|c|}
\hline & \multicolumn{4}{|c|}{ Physical function in older age } \\
\hline & \multicolumn{2}{|c|}{ Mobility limitations } & \multicolumn{2}{|c|}{ Physical impairment } \\
\hline & $\overline{\mathrm{OR}}$ & $95 \% \mathrm{Cl}$ & $\overline{\mathrm{OR}}$ & $95 \% \mathrm{Cl}$ \\
\hline \multicolumn{5}{|l|}{ Model 1} \\
\hline Upper white-collar ${ }^{a}$ ref. & & ref. & ref. & ref. \\
\hline Lower white-collar & 1.34 & $0.88-2.05$ & $1.67^{*}$ & $1.04-2.68$ \\
\hline Skilled blue-collar & $1.73^{*}$ & $1.09-2.73$ & $1.65^{\dagger}$ & $0.97-2.79$ \\
\hline Unskilled blue-collar & $1.51^{\dagger}$ & $0.98-2.31$ & $1.52^{+}$ & $0.93-2.48$ \\
\hline \multicolumn{5}{|c|}{ Model 2 Physical working conditions } \\
\hline Lower white-collar & $1.45^{+}$ & $0.94-2.22$ & $1.55^{\dagger}$ & $0.95-2.52$ \\
\hline Skilled blue-collar & $2.01^{* *}$ & $1.23-3.26$ & 1.43 & $0.81-2.50$ \\
\hline Unskilled blue-collar & $1.74^{*}$ & $1.10-2.75$ & 1.33 & $0.79-2.23$ \\
\hline \multicolumn{5}{|c|}{ Model 3 Psychosocial working conditions } \\
\hline \multicolumn{5}{|l|}{ Model 3 a Passive } \\
\hline Lower white-collar & 1.36 & $0.88-2.08$ & $1.52^{+}$ & $0.94-2.48$ \\
\hline Skilled blue-collar & $1.75^{*}$ & $1.09-2.82$ & 1.43 & $0.82-2.48$ \\
\hline Unskilled blue-collar & $1.53^{+}$ & $0.97-2.41$ & 1.25 & $0.74-2.13$ \\
\hline \multicolumn{5}{|l|}{ Model $3 b$ High-strain } \\
\hline Lower white-collar & 1.29 & $0.85-1.97$ & $1.68^{*}$ & $1.04-2.71$ \\
\hline Skilled blue-collar & $1.75^{*}$ & $1.11-2.77$ & $1.64^{\dagger}$ & $0.97-2.79$ \\
\hline Unskilled blue-collar & $1.47^{\dagger}$ & $0.96-2.26$ & $1.52^{\dagger}$ & $0.93-2.49$ \\
\hline \multicolumn{5}{|l|}{ Model 3c Low-strain } \\
\hline Lower white-collar & 1.28 & $0.84-1.96$ & $1.60^{+}$ & $0.99-2.58$ \\
\hline Skilled blue-collar & $1.67^{*}$ & $1.05-2.65$ & $1.56^{\dagger}$ & $0.93-2.70$ \\
\hline Unskilled blue-collar & 1.37 & $0.89-2.12$ & 1.38 & $0.83-2.27$ \\
\hline \multicolumn{5}{|l|}{ Model 3d Active } \\
\hline Lower white-collar & 1.37 & $0.89-2.11$ & $1.68^{*}$ & $1.03-2.73$ \\
\hline Skilled blue-collar & $1.77^{*}$ & $1.11-2.84$ & $1.66^{\dagger}$ & $0.96-2.86$ \\
\hline Unskilled blue-collar & $1.55^{\dagger}$ & $0.99-2.41$ & $1.54^{\dagger}$ & $0.92-2.55$ \\
\hline
\end{tabular}

Model 4 Physical and psychosocial working conditions

\begin{tabular}{lllll} 
Lower white-collar & 1.36 & $0.87-2.12$ & 1.42 & $0.86-2.37$ \\
Skilled blue-collar & $2.01^{* *}$ & $1.21-3.35$ & 1.28 & $0.71-2.31$ \\
Unskilled blue-collar & $1.61^{\dagger}$ & $0.98-2.63$ & 1.10 & $0.62-1.96$ \\
\hline
\end{tabular}

$p<0.10^{\dagger}, p<0.05^{*}, p<0.01^{* *}$. OR Odds Ratio, Cl Confidence Interval. All models are adjusted for age, sex, level of education, mobility, and health problems at baseline (Model 1). Model 2 was additionally adjusted for physical working conditions. Model 3 was adjusted like Model 1 and additionally for psychosocial working conditions. Model 4 was adjusted like Model 1 and additionally for physical and psychosocial working conditions. ${ }^{2}$ The reference category is upper white-collar workers in all models

impairment in older age when compared to lower social classes. Full mediation was observed by working conditions in the association between social class and physical impairment in older age, in which $35-74 \%$ of the total effect was attributable to working conditions. This mediating effect was primarily driven by passive jobs in bluecollar workers.
In accordance with previous research, our results show a social gradient in physical function in older age [30]. As expected, adverse physical working conditions are clustered in lower social groups, as are passive jobs (low demand combined with low control) [11]. The social gradient in health has previously been partially explained by several intermediary pathways such as material access, health behaviors, and working conditions [31, 32]. Our findings indicate that working conditions explain a high portion of the social gradient in physical impairment. This mediating effect was primarily driven by passive jobs in blue-collar workers. There is growing evidence of the long-term impact of adverse psychosocial working conditions on limitations in physical function in older age [15-17]. Passive jobs are unchallenging and may induce a loss of skills and unlearning. This could cause psychological atrophy and reduced self-efficacy. Low belief in own abilities has been linked to an unhealthy and passive lifestyle, e.g. passive jobs have been associated with a more passive lifestyle outside of work, such as physical inactivity [33]. Consequently, physical activity during leisure time may help preserve physical function in older age [34]. Moreover, passive jobs may be perceived as stressful. Understimulation has similar stress responses and symptoms to those that result from overstimulation [35]. Also, people in passive jobs can perceive even moderate psychological demands as stressful [36]. Increasing level of control at work, such as possibility to alter work positions/tasks (less monotonous work) and/or have the skills needed to be able to perform work tasks, may have beneficial effects on the physical body, as well as increasing level of self-efficacy. This, in turn, may also induce a more active lifestyle.

However, the weak support of physical working conditions as mediators was somewhat unexpected given previous research which suggested that physical working conditions play the largest role as mediator in the association between social class and physical function in older age $[37,38]$. A potential explanation for our findings may be the inclusion of a more recent cohort, namely, those still employed in 1991. Improvements in the physical work environment in Sweden may have contributed to the drivers of physical function in older age being substituted by primarily psychosocial factors in the work environment. Post hoc analyses excluding the third linkage from the dataset confirmed this assumption. Although not reaching traditional thresholds for declaring statistical significance $(p<.05)$, the patterns of the mediation analysis suggest that physical working conditions among blue-collar workers may be suppressing the true association between social class and mobility limitations in older age $(p<.10)$. A suppressor has been defined as "a variable which increases the predictive validity of 
Table 4 Decomposition of effects of social class on physical function in older age

\begin{tabular}{|c|c|c|c|c|c|c|c|c|}
\hline & \multicolumn{8}{|c|}{ Mediation analysis of working conditions } \\
\hline & \multicolumn{4}{|c|}{ Mobility limitations } & \multicolumn{4}{|c|}{ Physical impairment } \\
\hline & Total effects & Direct effects & Indirect effects & Mediation $\%^{\mathrm{a}}$ & Total effects & Direct effects & Indirect effects & Mediation $\%^{\mathrm{a}}$ \\
\hline \multicolumn{9}{|c|}{ Model 2 Physical working conditions (ref: upper white-collar) } \\
\hline Lower white-collar & 0.30 & $0.37^{\dagger}$ & -0.07 & -23.92 & $0.51^{*}$ & $0.44^{\dagger}$ & 0.08 & 14.63 \\
\hline Skilled blue-collar & $0.55^{*}$ & $0.70^{* *}$ & $-0.15^{\dagger}$ & -26.40 & $0.50^{\dagger}$ & 0.36 & 0.14 & 28.80 \\
\hline Unskilled blue-collar & $0.42^{\dagger}$ & $0.55^{*}$ & $-0.14^{\dagger}$ & -31.89 & $0.42^{\dagger}$ & 0.28 & 0.14 & 32.50 \\
\hline \multicolumn{9}{|c|}{ Model 3 Psychosocial working conditions } \\
\hline \multicolumn{9}{|c|}{ 3a Passive (ref: upper white-collar) } \\
\hline Lower white-collar & 0.30 & 0.30 & 0.00 & -3.05 & $0.51^{*}$ & $0.42^{+}$ & 0.09 & 17.59 \\
\hline Skilled blue-collar & $0.55^{*}$ & $0.56^{*}$ & -0.01 & -2.50 & $0.49^{\dagger}$ & 0.36 & $0.14^{\dagger}$ & 27.61 \\
\hline Unskilled blue-collar & $0.41^{\dagger}$ & $0.43^{\dagger}$ & -0.02 & -4.32 & $0.42^{+}$ & 0.23 & $0.19^{\dagger}$ & 45.71 \\
\hline \multicolumn{9}{|c|}{36 High-strain (ref: upper white-collar) } \\
\hline Lower white-collar & 0.30 & 0.26 & 0.04 & 14.41 & $0.51^{*}$ & $0.52^{*}$ & -0.01 & -1.64 \\
\hline Skilled blue-collar & $0.56^{*}$ & $0.56^{*}$ & -0.00 & -0.11 & $0.50^{\dagger}$ & $0.50^{\dagger}$ & 0.00 & 0.01 \\
\hline Unskilled blue-collar & $0.41^{\dagger}$ & $0.39^{\dagger}$ & 0.02 & 5.98 & $0.42^{\dagger}$ & $0.42^{\dagger}$ & -0.00 & -0.91 \\
\hline \multicolumn{9}{|c|}{ 3c Low-strain (ref: upper white-collar) } \\
\hline Lower white-collar & 0.29 & 0.25 & 0.04 & 15.20 & $0.51^{*}$ & $0.47^{\dagger}$ & 0.04 & 8.50 \\
\hline Skilled blue-collar & $0.55^{*}$ & $0.51^{*}$ & 0.04 & 6.54 & $0.50^{\dagger}$ & $0.46^{\dagger}$ & 0.04 & 7.19 \\
\hline Unskilled blue-collar & $0.41^{\dagger}$ & 0.37 & $0.10^{\dagger}$ & 23.38 & $0.42^{\dagger}$ & 0.32 & 0.10 & 23.92 \\
\hline \multicolumn{9}{|c|}{ 3d Active (ref: upper white-collar) } \\
\hline Lower white-collar & 0.30 & 0.32 & -0.02 & -8.13 & $0.51^{*}$ & $0.52^{*}$ & -0.01 & -1.61 \\
\hline Skilled blue-collar & $0.54^{*}$ & $0.57^{*}$ & -0.03 & -5.15 & $0.50^{\dagger}$ & $0.51^{\dagger}$ & -0.01 & -1.97 \\
\hline Unskilled blue-collar & $0.41^{\dagger}$ & $0.53^{+}$ & -0.03 & -7.33 & $0.42^{\dagger}$ & $0.43^{\dagger}$ & -0.01 & -2.57 \\
\hline \multicolumn{9}{|c|}{ Model 4 Physical and psychosocial working conditions (ref: upper white-collar) } \\
\hline Lower white-collar & 0.31 & 0.28 & 0.02 & 7.92 & $0.52^{*}$ & 0.33 & $0.18^{\dagger}$ & 35.35 \\
\hline Skilled blue-collar & $0.56^{*}$ & $0.60^{*}$ & -0.04 & -8.00 & $0.50^{\dagger}$ & 0.25 & $0.26^{*}$ & 50.91 \\
\hline Unskilled blue-collar & $0.43^{\dagger}$ & $0.42^{+}$ & 0.01 & 3.00 & $0.42^{\dagger}$ & 0.11 & $0.31^{*}$ & 73.69 \\
\hline
\end{tabular}

${ }^{a}$ Mediation \% corresponds to conf_pct in khb decomposition output in STATA 14 which stands for confounding percentage net of rescaling $p<0.10^{\dagger}, p<0.05^{*}$, $p<0.01^{* *}$. Effect size expressed as beta coefficients unless otherwise specified. All models were adjusted for age, sex, level of education, mobility, and health problems at baseline (Model 1). Model 2 was additionally adjusted for physical working conditions. Model 3 was adjusted like Model 1 and additionally for psychosocial working conditions. Model 4 was adjusted like Model 1 and additionally for physical and psychosocial working conditions

another variable (or set of variables) by its inclusion in a regression equation" [39]. This may be a consequence of the distribution of physical working conditions among social classes, with lower social groups characteristically exposed to a harsher physical work environment. Hence, failure to account for these working conditions may result in an underestimation of the true magnitude of the relationship between social class and self-reported mobility limitations in older age [40]. This interpretation could explain the role of physical working conditions in our regression models but as the indirect values were statistically non-significant $(p<.05)$, it may be imprecise and inconclusive. Contrastingly, physical working conditions moderately attenuated the association between social class and physical impairment in older age. This may indicate that the advantage upper white-collar workers have over blue-collar workers, with respect to physical performance in older age, may be explained by the variations in physical environments across occupational classes. A possible explanation could be that the performance tests that evaluated physical performance were of the same body parts that undergo strain throughout working life in physically demanding jobs, compared to self-reported mobility limitations. Given that adverse physical working conditions are most common in blue-collar workers, as are passive jobs, the mediating effect of passive jobs may be influenced by observed and unobserved factors in the physical work environment. Variations in the role of the physical work environment on the social gradient of selfreported mobility limitations and objectively measured physical impairment highlight the need to capture both subjective and objective measures of outcome [41]. 


\section{Limitations and strengths}

Strengths of this study include the high response rates in both the LNU (78-91\%) and the SWEOLD (86-95\%) survey, the use of a national random sample, the long follow-up (20-24 years) of the same participants and the inclusion of both self-reported mobility and objective tests of physical function as dependent variables $[42,43]$. The data used have been extensively cited [8, 9, 44]. Nevertheless, the results should be interpreted with caution due to some methodological considerations. First, selective attrition must always be considered in longitudinal studies. The loss of participants due to mortality (selective survival, i.e. those who are better off survive longer) or dropout could lead to under- or overestimation of the true association. However, telephone and proxy interviews could help address the selective attrition bias by including the most disabled participants in the sample [45]. Also, imputations were performed for performance tests by using information gathered during interviews on ADL in order to minimize exclusion of older adults with the poorest health. Such imputations may introduce a misclassification bias. However, very few were imputed (5\%) and it is very likely that a person that is not able to carry out one or more ADL would have severe difficulties to carry out the physical performance tests [6]. Another source of selection bias could be the 'healthy worker effect', i.e. people who have the capacity to work are retained in the workforce [46]. Including people that worked passed official retirement ages may have further strengthen this selection bias. This may result in an underestimation of the true association as people with worse health have left the workforce (possibly attributable to adverse working conditions) and have not been included in the study. Moreover, type of occupation may also be influenced by health status [47]. We did not have the possibility to adjust for health prior to baseline. However, adjusting for mobility and health problems at baseline is a way of accounting for at least some of these pre-existing conditions in order to minimize the effect of undetected reverse causation between health and occupation.

Second, the questions used for assessing psychosocial working conditions were limited. The original questionnaire was developed and expanded in 1991 to include other dimensions of work stress [48]. Unfortunately, the additional information needed for the expanded questionnaire was unavailable in the early waves of the Level of Living Surveys. As the cohorts of this study are from 1986 to 1991, they may not depict the most accurate image of current psychosocial work stress. However, these questions were used by Karasek to create the original demand-control model [27]. Recent research also indicates that the dimensions of demand and control continue to be a valid measure of the psychosocial work environment and are relevant to occupational health [49]. Finally, although the long gap between baseline and follow-up present some advantages with respect to the assessment of the long-term impact of social class on physical function, it also has limitations. Particularly as it does not reveal a possible change in social class or working conditions between baseline (mean age 59) and age at retirement. However, there was little work mobility in this cohort [50] and at the ages that working conditions were assessed [51], and most likely the participants have already reached their highest achieved occupation-based social class.

\section{Potential implications}

The implications of this study extend to the working population with comparable social and political contexts. Globally, low skilled and non-routine manual labor corresponding to blue-collar jobs still make up $45 \%$ of total employment [52]. These groups will be major contributors to the aging population and we must find ways to encourage healthy aging among them. The early identification of harmful indicators in the work environment may help in the design of efficient workspaces for the future. Ongoing efforts towards creating safer physical work environments must be encouraged, but there is also a need to address the psychosocial aspects of the workplace.

\section{Conclusions}

To conclude, the results highlight the importance of working conditions in combating the social gradient in physical function in older age, contributing to evidence on the magnitude of impact exerted by both the physical and psychosocial work environment separately and in conjunction. By following the same participants for over 20 years, this study reveals the need for a life-course perspective when investigating predictors of healthy aging.

\section{Abbreviations \\ ADL: Activities of Daily Living; Cl: Confidence Interval; KHB: Karlson, Holm, and Breen command; LNU: The Level of Living Survey; OR: Odds Ratio; SEl: Swedish Socioeconomic Index; SWEOLD: The Swedish Panel Study of Living Conditions of the Oldest Old}

\section{Acknowledgements}

Not applicable.

\section{Authors' contributions}

NP processed the data, carried out the statistical analyses, and drafted and finalized the manuscript. CN supervised the first author in statistical analyses. All authors participated in the conception and design of the study and the interpretation of the data and revised the manuscript. All authors have read and approved the final manuscript.

\section{Funding}

This study was done as part of the project "Psychosocial working conditions and late-life physical functioning: What role do gender, socioeconomic position, work-life balance, and coping play", which has received financial support from The Marcus and Marianne Wallenberg Foundation (grant number 
MMW 2016.0081), and as part of the project "The fruits of labor: Investigating the influence of working conditions on the initiation and duration of the fourth age", which has received financial support from Forte, Swedish Council for Working Life and Social Research (grant number 2019-01141). The funding bodies had no role in the design of the study or the collection, analysis, interpretation of data, or in writing the manuscript. Open Access funding provided by Karolinska Institutet.

\section{Availability of data and materials}

The datasets used and/or analyzed during the current study are available from the corresponding author on reasonable request. Public access to the database may be given if applicants have a scientific affiliation, sign a statement that the data will only be used for scientific purposes, and that the scientific project have ethical approval. Applicable sections of The Swedish Research Council (VR) principles for conducting research in humanities and the social sciences must be adhered to (http://www.codex.vr.se/en/forskninghumsam.shtml). Data will be available after the above-mentioned documents have been received, by email at the SWEOLD Research Data Center dataaccess@sweold.se More information can be found at www.sweold.se.

\section{Ethics approval and consent to participate}

The project is covered by ethical approval from the Uppsala University Hospital Ethical Committee (DNR 247/91 and DNR 4010-91), the Ethical Research Committee of Karolinska Institutet (DNR 03-413) and the Regional Ethical Review Board in Stockholm (EPN DNR 2010/403-31/4). A relative (normally a spouse or an adult child) signed the consent form for participants who were physically or cognitively too impaired to sign the form at the time of the interview.

\section{Consent for publication}

Not applicable.

\section{Competing interests}

The authors declare that they have no competing interests.

\section{Received: 31 March 2020 Accepted: 23 August 2020}

Published online: 04 September 2020

\section{References}

1. World Health Organization. World report on ageing and health. 2015. https:/apps.who.int/iris/bitstream/handle/10665/186463/9789? sequence=1. Accessed 18 Dec 2018.

2. Jagger C, Collerton JC, Davies K, Kingston A, Robinson LA, Eccles MP, et al. Capability and dependency in the Newcastle $85+$ cohort study. Projections of future care needs. BMC Geriatr. 2011:11(1):21.

3. Rosso AL, Taylor JA, Tabb LP, Michael YL. Mobility, disability, and social engagement in older adults. J Aging Health. 2013;25(4):617-37.

4. Santoni G, Angleman SB, Ek S, Heiland EG, Lagergren M, Fratiglioni L, et al. (2018). Temporal trends in impairment of physical function among older adults during 2001-16 in Sweden: towards a healthier ageing. Age Ageing. 2018;47(5):698-704.

5. Young A. Ageing and physiological functions. Philos Trans R Soc Lond Ser B Biol Sci. 1997;352(1363):1837-43.

6. Guralnik JM, Ferrucci L, Simonsick EM, Salive ME, Wallace RB. Lowerextremity function in persons over the age of 70 years as a predictor of subsequent disability. N Engl J Med. 1995 Mar 2;332(9):556-61.

7. Bentley JP, Brown CJ, McGwin G Jr, Sawyer P, Allman RM, Roth DL. Functional status, life-space mobility, and quality of life: a longitudinal mediation analysis. Qual Life Res. 2013;22(7):1621-32.

8. Darin-Mattsson A, Fors S, Kåreholt I. Different indicators of socioeconomic status and their relative importance as determinants of health in old age. Int J Equity Health. 2017;16(1):173.

9. Huisman M, Kunst AE, Mackenbach JP. Socioeconomic inequalities in morbidity among the elderly; a European overview. Soc Sci Med. 2003;57(5):861-73.

10. Lennartsson C, Eyjólfsdóttir HS, Celeste RK, Fritzell J. Social class and infirmity. The role of social class over the life-course. SSM Popul Health. 2017 Dec 21:4:169-77.

11. Solar O, Irwin A. A conceptual framework for action on the social determinants of health. Social Determinants of Health Discussion Paper 2 (Policy and Practice): World Health Organization; 2010. https://www.who.int/
sdhconference/resources/ConceptualframeworkforactiononSDH_eng. pdf?ua=1. Accessed 14 Dec 2018

12. Ferraro KF, Morton PM. What do we mean by accumulation? Advancing conceptual precision for a core idea in gerontology. J Gerontol B Psychol Sci Soc Sci. 2018;73(2):269-78.

13. Galobardes B, Shaw M, Lawlor DA, Lynch JW, Davey SG. Indicators of socioeconomic position (part 1). J Epidemiol Community Health. 2006;60(1): 7-12.

14. Landsbergis PA, Choi B, Dobson M, Sembajwe G, Slatin C, Delp L, et al. The key role of work in population health inequities. Am J Public Health. 2018; 108(3):296-7.

15. Kulmala J, Hinrichs T, Törmäkangas T, von Bonsdorff MB, von Bonsdorff ME, Nygård $\mathrm{CH}$, et al. Work-related stress in midlife is associated with higher number of mobility limitation in older age-results from the FLAME study. Age (Dordr). 2014;36(6):9722.

16. Nilsen C, Andel R, Darin-Mattsson A, Kåreholt I. Psychosocial working conditions across working life may predict late-life physical function: a follow-up cohort study. BMC Public Health. 2019;19(1):1125.

17. Wahrendorf M, Sembajwe G, Zins M, Berkman L, Goldberg M, Siegrist J. Long-term effects of psychosocial work stress in midlife on health functioning after labor market exit-results from the GAZEL study. J Gerontol B Psychol Sci Soc Sci. 2012;67(4):471-80

18. McEwen BS. Central effects of stress hormones in health and disease: understanding the protective and damaging effects of stress and stress mediators. Eur J Pharmacol. 2008:583(2-3):174-85.

19. Gnudi S, Sitta E, Gnudi F, Pignotti E. Relationship of a lifelong physical workload with physical function and low back pain in retired women Aging Clin Exp Res. 2009;21:55-61.

20. Kristensen P. Inequalities in health, social causation and the role of occupation. Scand J Work Environ Health. 2008;34(4):235-8.

21. Burgard SA, Lin KY. Bad jobs, bad health? How work and working conditions contribute to health disparities. Am Behav Sci. 2013;57(8):10. 1177/0002764213487347

22. Clougherty JE, Souza K, Cullen MR. Work and its role in shaping the social gradient in health. Ann N Y Acad Sci. 2010;1186:102-24.

23. Nixon AE, Mazzola JJ, Bauer J, Krueger JR, Spector PE. Can work make you sick? A meta-analysis of the relationships between job stressors and physical symptoms. Work Stress. 2011:25(1):1-22.

24. Jonsson J, Mills C. Cradle to grave. Life-course change in modern Sweden. Durham: Sociology Press; 2001.

25. Lennartsson C, Agahi N, Hols-Salén L, Kelfve S, Kåreholt I, Lundberg O, et al. Data resource profile: the Swedish panel study of living conditions of the oldest old (SWEOLD). Int J Epidemiol. 2014;43(3):731-8.

26. Erikson $\mathrm{R}$, Goldthorpe $\mathrm{JH}$. The constant flux. A study of class mobility in industrial societies. Oxford: Clarendon Press; 1992.

27. Karasek R, Baker D, Marxer F, Ahlbom A, Theorell T. Job decision latitude, job demands, and cardiovascular disease: a prospective study of Swedish men. Am J Public Health. 1981;71(7):694-705.

28. Breen R, Karlson KB, Holm A. Total, direct, and indirect effects in Logit and Probit models. Sociol Methods Res. 2013;42(2):164-91.

29. Zhao X, Lynch JG, Chen Q. Reconsidering baron and Kenny: myths and truths about mediation analysis. J Consum Res. 2010;37(2):197-206.

30. Mackenbach JP, Stirbu I, Roskam AJ, Schaap MM, Menvielle G, Leinsalu M, et al. Socioeconomic inequalities in health in 22 European countries [published correction appears in N Engl J med. 2008 Sep 18;359(12):e14]. N Engl J Med. 2008;358(23):2468-81.

31. Borg V, Kristensen TS. Social class and self-rated health: can the gradient be explained by differences in life style or work environment? Soc Sci Med. 2000;51(7):1019-30.

32. Lallukka T, Lahelma E, Rahkonen O, Roos E, Laaksonen E, Martikainen P, et al. Associations of job strain and working overtime with adverse health behaviors and obesity: evidence from the Whitehall II study, Helsinki health study, and the Japanese civil servants study. Soc Sci Med. 2008;66(8):1681-98.

33. Staines GL. Spillover versus compensation: a review of the literature on the relationship between work and nonwork. Hum Relations. 1980;33(2):111-29.

34. Pieper C, Schröer S, Eilerts AL. Evidence of workplace interventions-a systematic review of systematic reviews. Int J Environ Res Public Health. 2019:16(19):3553.

35. Frankenhaeuser M, Nordheden B, Myrsten AL, Post B. Psychophysiological reactions to understimulation and overstimulation. Acta Psychol. 1971;35(4): 298-308. 
36. Karasek R, Theorell T. Healthy work. Stress, productivity, and the reconstruction of working life. New York: Basic Books; 1990.

37. Parker V, Andel R, Nilsen C, Kåreholt I. The association between mid-life socioeconomic position and health after retirement - exploring the role of working conditions. J Aging Health. 2013;25(5):863-81.

38. Schrijvers CTM, van de Mheen HD, Stronks K, Mackenbach JP. Socioeconomic inequalities in health in the working population: the contribution of working conditions. Int J Epidemiol. 1998;27(6):1011-8

39. Tzelgov J, Henik A. Suppression situations in psychological research: definitions, implications, and applications. Psychol Bull. 1991;109(3):524-36.

40. MacKinnon DP, Krull JL, Lockwood CM. Equivalence of the mediation, confounding and suppression effect. Prev Sci. 2000;1(4):173-81.

41. Iburg KM, Salomon JA, Tandon A, Murray CJL, Policy WHOGP on E for H. Cross-population comparability of self-reported and physician-assessed mobility levels: evidence from the third National Health and Nutrition Examination Survey /cKim M. Iburg ... [et al.]: World Health Organization; 2001. https:/apps.who.int/iris/handle/10665/67776. Accessed 14 Sept 2018

42. Guralnik JM, Branch LG, Cummings SR, Curb JD. Physical performance measures in aging research. J Gerontol. 1989;44(5):M141-6.

43. Machón M, Vergara I, Dorronsoro M, Vrotsou K, Larrañaga I. Self-perceived health in functionally independent older people: associated factors. BMC Geriatr. 2016:16(1):66

44. Nilsen C, Andel R, Fors S, Meinow B, Darin Mattsson A, Kåreholt I. Associations between work-related stress in late midlife, educational attainment, and serious health problems in old age: a longitudinal study with over 20 years of follow-up. BMC Public Health. 2014;14:878.

45. Kelfve S, Thorslund M, Lennartsson C. Sampling and non-response bias on health-outcomes in surveys of the oldest old. Eur J Ageing. 2013 Mar 26: 10(3):237-45.

46. Virtanen P, Liukkonen V, Vahtera J, Kivimäki M, Koskenvuo M. Health inequalities in the workforce: the labour market core-periphery structure. Int J Epidemiol. 2003;32(6):1015-21.

47. Hoffmann R, Kröger H, Geyer S. Social causation versus health selection in the life course: does their relative importance differ by dimension of SES? Soc Indic Res. 2019:141(3):1341-67.

48. Sanne B, Torp S, Mykletun A, Dahl AA. The Swedish demand-controlsupport questionnaire (DCSQ): factor structure, item analyses, and internal consistency in a large population. Scand J Public Health. 2005;33(3):166-74

49. Åhlin JK, Westerlund H, Griep Y, Magnusson Hanson LL. Trajectories of job demands and control: risk for subsequent symptoms of major depression in the nationally representative Swedish longitudinal occupational survey of health (SLOSH). Int Arch Occup Environ Health. 2018;91(3):263-72.

50. Oyer P. Wage structure and labor mobility in Sweden, 1970-90. In: The structure of wages: an international comparison . National Bureau of Economic Research, Inc. Massachusetts: University of Chicago Press; 2009. p. 419-47.

51. Östh J, NiedomysI T, Amcoff J, Ander L, Hedberg S. Arbetsmarknad i förändring —en analys av regionala branschförändringar över tid och dess betydelse för framtida arbetsmiljöarbete [Labor market in change-analyses of regional industry changes and the meaning for future work environment policies]. Swedish Work Environ Authority. 2011;12 https://www.av.se/ globalassets/filer/publikationer/kunskapssammanstallningar/arbetsmarknad-iforandring-kunskapssammanstallningar-rap-2011-12.pdf. Accessed 13 Sept 2018.

52. International Labour Organization. World Employment and Social Outlook: Trends 2015. https:/www.ilo.org/wcmsp5/groups/public/-dgreports/dcomm/-publ/documents/publication/wcms_337069.pdf. Accessed 14 Sept 2018

\section{Publisher's Note}

Springer Nature remains neutral with regard to jurisdictional claims in published maps and institutional affiliations.

Ready to submit your research? Choose BMC and benefit from:

- fast, convenient online submission

- thorough peer review by experienced researchers in your field

- rapid publication on acceptance

- support for research data, including large and complex data types

- gold Open Access which fosters wider collaboration and increased citations

- maximum visibility for your research: over $100 \mathrm{M}$ website views per year

At $\mathrm{BMC}$, research is always in progress.

Learn more biomedcentral.com/submissions 